\title{
DISPONIBILIDADE DE INFORMAÇÕES PEDAGÓGICAS DE CURSOS DE PSICOLOGIA BRASILEIROS EM SITES DE INSTITUIÇÕES DE ENSINO SUPERIOR: UM ESTUDO SOBRE ACCOUNTABILITY
}

\author{
AUTOR: VICTORIA DOURADO MARTINS \\ CO-AUTOR: CAIO RUDA DE OLIVEIRA \\ CO-AUTOR/ORIENTADOR: GABRIELA ANDRADE DA SILVA
}

\begin{abstract}
Resumo: A disponibilização de informações pedagógicas em Instituições de Ensino Superior (IES) é assegurada pela Lei de Acesso à Informação e Lei de Diretrizes e Bases - LDB. O conceito de accountability configura a justificação de valor e qualidade do sistema às esferas interessadas e, portanto, também decorre da acessibilidade de informações. $O$ objetivo do presente trabalho foi analisar a disponibilidade de informações pedagógicas - Projeto Pedagógico do Curso (PPC), Matriz Curricular (MC), Planos de Ensino-Aprendizagem (PEA), ementas e bibliografias - nos sites das IES, à luz dos conceitos de transparência e accountability. Trata-se de estudo quantitativo, documental, que analisou sítios eletrônicos dos cursos de bacharelado em Psicologia brasileiros, ativos no E-MEC no dia 1/4/2018, resultando em 800 cursos. Cada curso foi examinado por dois estudantes de graduação, de forma independente e cega, obtendo taxa de concordância de $87,7 \%$ para PPCs, 71,5\% para MCs, 96,0\% para PEAs, 85,2\% para ementas e $91,3 \%$ para bibliografias - todas consideradas aceitáveis, por serem superiores a $70 \%$. Observou-se a incipiente presença da maioria das informações pedagógicas em todo o território nacional. Os cursos foram analisados quanto à presença de informações por macrorregião e categoria administrativa da IES. Constatou-se maior publicização de PPCs $(30,4 \%)$ e ementas $(19,6 \%)$ no Norte, de MCs no Sul $(76,3 \%)$, de PEAs e bibliografias no Sudeste (5,3\%). Testes de qui-quadrado de Pearson identificaram associações significativas entre a presença de PPCs e MCs e a macrorregião onde se localiza o curso, mas não quanto aos PEAs, ementas e bibliografias. Ademais, observou-se que todos os tipos de informações pedagógicas analisados estiveram presentes com maior frequência nos sites das IES públicas, quando comparado às demais categorias (privadas com e sem fins lucrativos), revelando diferenças estatisticamente significativas no teste de qui-quadrado de Pearson. Entende-se que a omissão das informações pedagógicas nos sites institucionais constitui uma limitação de veiculação de informações necessárias para aspirantes à graduação em Psicologia, estudantes regulares e comunidade em geral, além de descumprir a LDB. Para além de questões burocráticas, a disponibilização dessa informações é essencial para a accountability e para a afiliação dos estudantes e potencializa pesquisas documentais sobre a educação no país.
\end{abstract}

Palavras-chave: Formação do Psicólogo, Ensino Superior, Transparência, Accountability. 